\title{
The benefits of integrating long-term tailings and mine plans
}

\author{
JP Coffey Rio Tinto, Australia \\ JD Plunkett Rio Tinto, Australia
}

A Carneiro Rio Tinto, Australia

\begin{abstract}
Tailings management plays a significant role in the overall risk profile of mining operations, and there are significant measurable financial, reputational and sustainability benefits associated with achieving leading practice that effectively reduces the risks related to tailings storage facilities (TSFs). Recent TSF failure investigation reports and other literature have emphasised the need to consider innovative means for tailings management to facilitate a reduction of risk, but it appears likely that improved safety performance of TSFs will not only be achieved through advances in design methods, but also in selection of storage options that seek to reduce the consequence of facility failure. To this end, strategic planning in which large horizons of time and varying inter-dependencies of the components that make up the tailings operation are considered is essential. While this is widely acknowledged, there are limited published examples of how mining companies apply strategic planning considering whole-of-life comparisons linking the integration of TSFs embedded within the mine plan. This paper presents a set of case studies where significant benefits have been or are being realised through the integration of long-term tailings and mine planning functions at Rio Tinto Iron Ore mine sites. This has been made possible through the ongoing update of a tailings management plan which includes key inputs from a multi-disciplinary team. It is suggested that the discussion and data presented in this paper will serve to demonstrate that reducing risk, and even costs, is often possible in parallel through strong planning and integration with other disciplines.
\end{abstract}

Keywords: tailings, risk, cost, strategic planning

\section{Introduction}

Tailings are variously defined as residues created as part of mining, refining, smelting and water treatment processes (Rio Tinto 2020). They consist of the processed rock or soil left over from the separation of the minerals and metals of value from the rock or soil within which they occur (Global Tailings Review 2020). Therefore, tailings are by definition a by-product of mining that results from mineral processing and are, at this stage and despite progressive advances in technologies which provide alternative tailings management methods (Edraki et al. 2014; Jewell \& Fourie 2015; Van Zyl 2016), a necessary part of doing business.

Tailings management plays a significant role in the overall risk profile of mining operations. Managing the risk posed by their storage is therefore a key function for any mining company. Recently, and more than ever, the mining industry is being increasingly challenged to improve tailings management. The recurrence of tailings storage facility (TSF) failures in recent years has created a crisis in terms of a loss of confidence and trust associated with the design, construction, operation and closure of such facilities (Morgenstern 2018). Combined with calls for the adoption of best available technologies (Morgenstern et al. 2015) such as paste thickening and filtration which improve the strength, reduce brittleness and mobility in addition to myriad other potential benefits (Fourie 2012; Jewell \& Fourie 2015), it appears likely that improved safety performance of TSFs will not only be achieved through advances in design methods, but also in selection of storage options that seek to reduce the consequence of facility failure. As an example, this is suggested by the requirement for multi-criteria analysis for selection of storage methods in the recently published Global Industry Tailings Standard on Tailings Management (Global Tailings Review 2020). 
The selection of tailings storage options that improve safety, environmental, and economic performance starts with strategic planning in which large horizons of time and varying inter-dependencies of the components that make up the tailings operation are considered. The fact that the successful planning and management of TSFs could greatly benefit from tailings management integrated into mine planning, operations and closure has long been recognised (International Commission on Large Dams 2001). It is widely acknowledged in guidelines and other published literature that TSF design should be integrated within the life-of-mine (LOM) plan, so that the most cost-effective and acceptable risk solution can be developed (Department of Foreign Affairs and Trade 2016; Mining Association of Canada 2019; Australian National Committee on Large Dams (ANCOLD) 2012; Morgenstern et al. 2015). Without this long-term integration, the owner is limiting its opportunity to achieve successful operation and closure of the TSFs within its portfolio. However, there appears to be very limited published examples of how mining companies actually apply strategic planning considering whole-of-life comparisons linking the integration of TSFs embedded within the mine plan.

Aiming at filling this current gap, this paper reports on significant benefits that have been or are being realised through the integration of long-term tailings and mine planning functions at the Rio Tinto Iron Ore (RTIO) mine sites in the Pilbara region of Western Australia. The development of a LoM tailings management strategy has assisted with more holistic evaluations for the selection of lower risk and more cost-effective storage options in comparison with storage into more traditional cross-valley and paddock style facilities that have historically been operated by RTIO. The approach to developing an integrated tailings management plan (TMP) which aligns with the mine plan has made it possible to identify opportunities for tailings storage within exhausted mine voids or integration with coarse waste streams. Although these alternative storage methods typically require greater integration into mine and capital planning functions, they can pose a lower consequence should a TSF failure ever occur and have been proving to be more economical over the long-term. It is acknowledged that the use of mining voids for tailings storage is not always possible due to the nature of mining at any given operation, however it is suggested that the discussion and data presented in this paper will still serve to demonstrate that reducing risk and even cost is often possible in parallel through strong planning and integration with other disciplines.

\section{Overview of the TSFs operated by Rio Tinto Iron Ore}

A total of 15 TSFs were selected to be included in the analyses conducted for the purposes of this paper. They were selected on the following basis:

1. A detailed consequence assessment was available.

2. Construction has occurred since 2013.

3. Detailed capital cost breakdowns were available.

Point 3 was important as no adjustment of capital costs for inflation has been made to the cost data presented. It is also important to note that only capital and operational costs were included in the analyses. Closure costs, albeit very important to be considered in the evaluation of tailings management options and which can ultimately affect the finances of a TSF project (Carneiro \& Fourie 2020), have been excluded from the discussion presented in this paper.

The following terms were used to classify the TSF types used throughout the paper and are provided as each does not appear to have one widely accepted across the industry:

- In-pit TSF - impoundment by remnant pit walls on all sides.

- In-pit TSF with embankments - impoundment with a mix of remnant pit walls and embankments either constructed by mine fleet or civil contractor.

- Ex-pit TSF - impoundment outside pit voids with construction of embankments at least partially by a civil contractor and most cases entirely by a civil contractor. 
The integration of tailings with coarse mine waste streams alluded to in the introduction fits within the in-pit TSF with embankments category above. In many cases, the embankments have been constructed of mine waste with mine fleet and as such are designed to be free-draining rather than to incorporate low-permeability zones.

Of the 15 TSFs considered in this study, 14 are included in the public disclosure made by Rio Tinto in 2021 (Rio Tinto 2021), with the remaining facility currently in the planning phase. As such, the capital costs for the additional TSF presented here is based on project estimates, and not on actual realised costs as is the case for the other TSFs.

Figure 1 presents the composition of TSF types considered in this paper. All but one of the in-pit TSFs with embankments have relatively little of their perimeter impoundment provided by constructed embankments, with the portion of the TSFs' perimeters comprising constructed embankments varying from approximately 6 to $35 \%$. One of the ex-pit TSFs is actually built within a previously mined area, but has $100 \%$ of its perimeter impoundment provided by constructed embankments to at least some portion of its height.

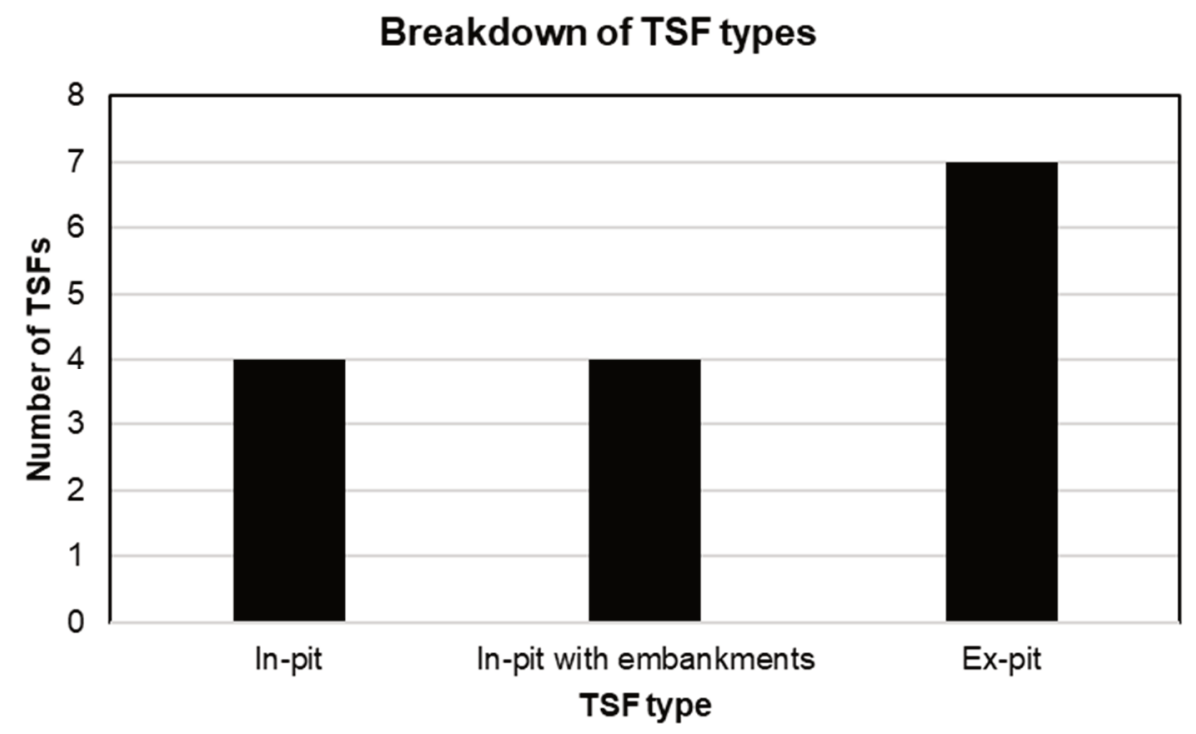

Figure 1 Number of facilities for each of the TSF type

The consequence associated with failure of each of the 15 TSFs based on the consequence classifications of ANCOLD (2012) is presented in Figure 2. Further detail on the risk profile of each of the TSF types is presented in Figure 3. It is evident for the selected facilities that the consequence of failure is generally lower for in-pit TSFs and higher for the other two types. The risks associated with in-pit TSFs are typically environmental and production related, with a population at risk (PAR) of less than 1, which results in the Very Low/Low classifications. The High C consequence categories for in-pit TSFs with embankments typically arises due to ongoing mining activity downstream of the TSF presenting a PAR of greater than one. However, once mining has ceased downstream of the in-pit TSFs with embankments the consequence of failure should be significantly reduced. 


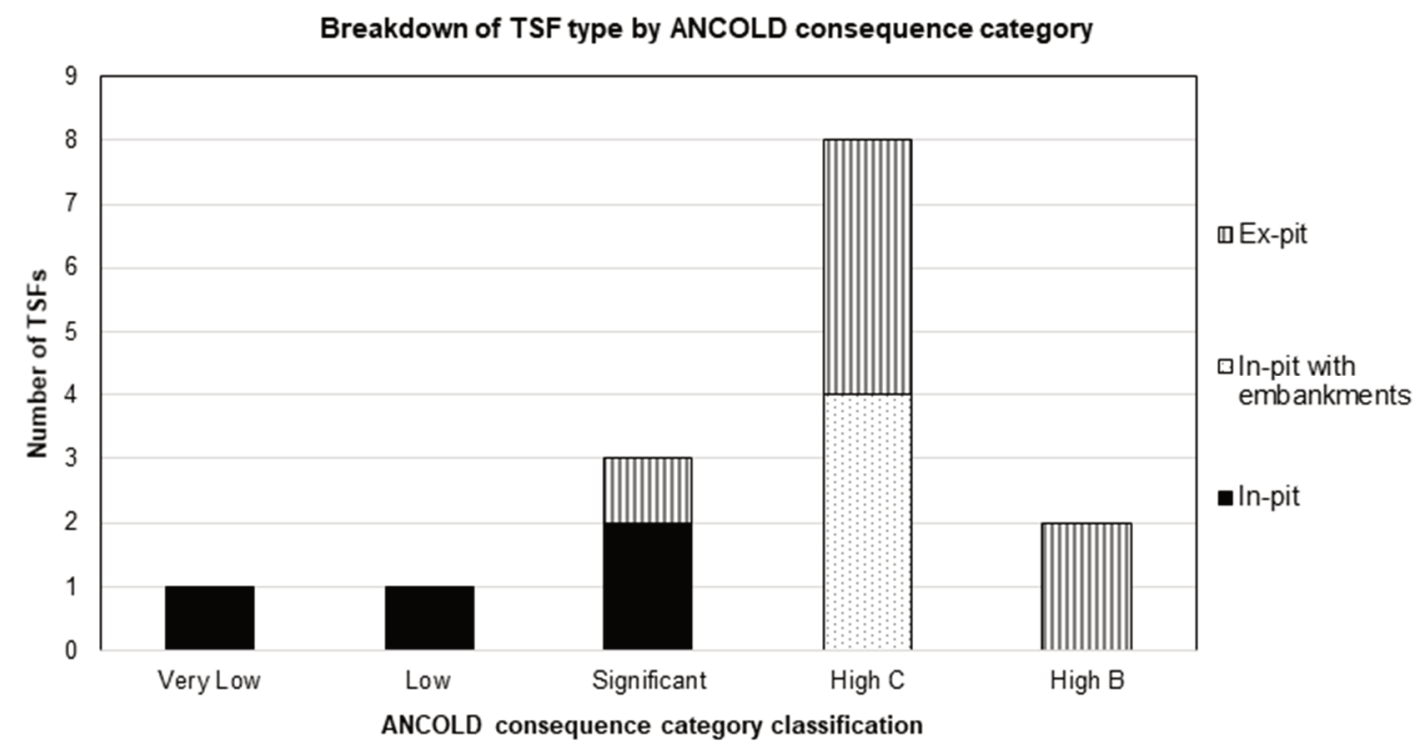

Figure 2 Number of facilities grouped into different TSF types for each ANCOLD consequence category

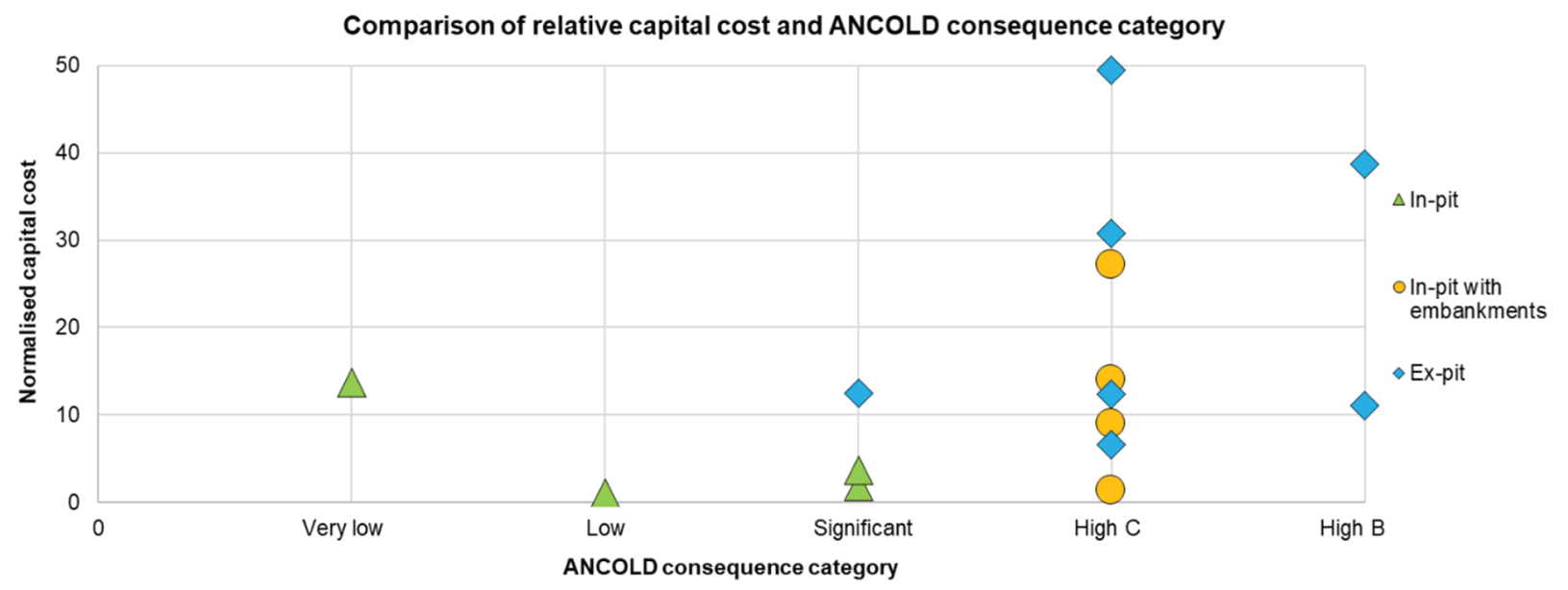

Figure 3 Comparison of ANCOLD consequence classification and normalised capital cost for the construction of the TSFs

Figure 4 shows the comparison of the capital costs for construction of the 15 TSFs. As can be seen, costs have varied significantly. For the purposes of presentation in this paper, all capital costs have been normalised against the lowest unit rate (capital cost per dry tonne of tailings stored). It is clear from the comparison of the capital costs that in-pit TSFs present the lowest unit rate, whereas significant overlap between in-pit TSFs with embankments and ex-pit TSFs is evident. The capital cost of in-pit TSFs with embankments is significantly influenced by the portion of the perimeter impoundment that is comprised of constructed embankments. However, the significant costs can also arise from construction by mine fleet either by inefficiency in dumping to facilitate compliance with an earthworks specification or greater haulage distances for waste (both resulting in increased cycle times for the mining process), or for construction of pipeline corridors through active mining areas. Although only anecdotal as a detailed economic analysis has not been undertaken, the costs of the various projects also appear to have been significantly influenced by the rates able to be secured in the engagement of civil and mechanical contractors, which in turn appears somewhat correlated with the spot price of iron ore. 


\section{Relative capital cost comparison of TSF types}

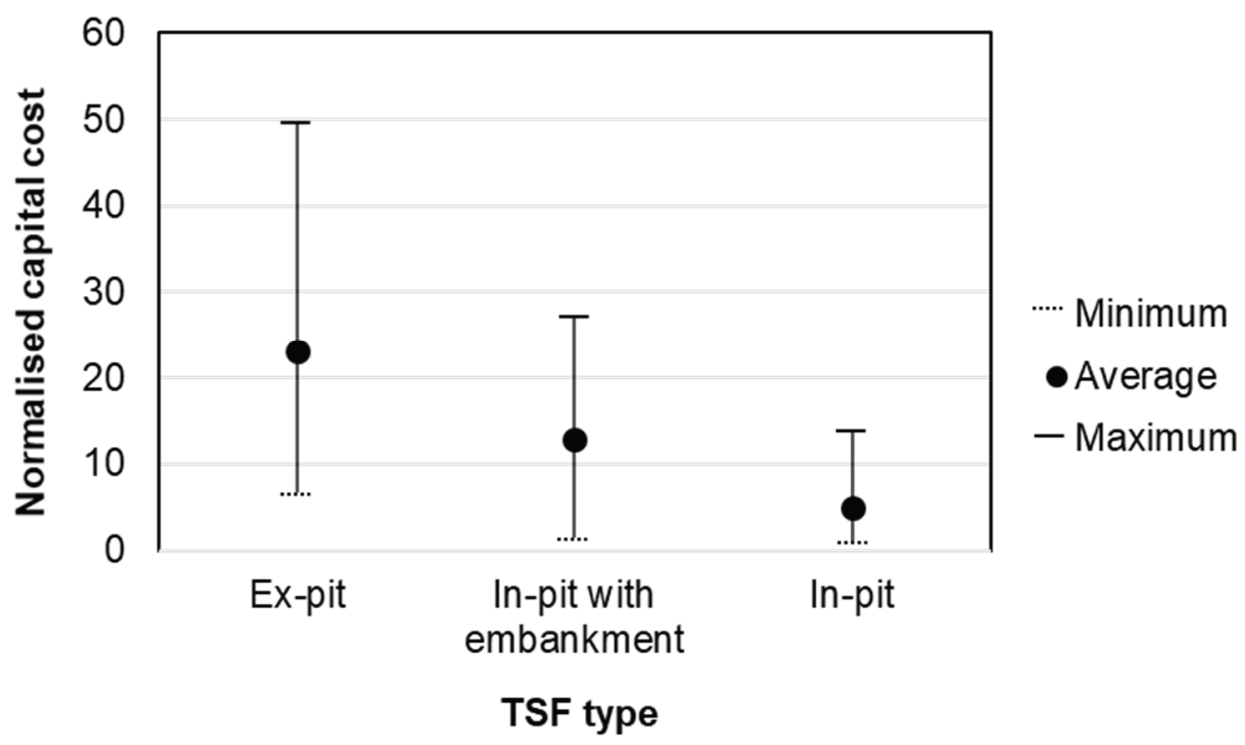

Figure 4 Relative capital costs for construction of the facilities classified by TSF type

There is significant variance in the capital cost of in-pit TSF construction, with the average unit capital cost (5.01) being approximately five times the lowest unit capital cost (1.0), which is illustrated in the right-hand column of Figure 3. This is heavily influenced by the relative size of storage and distance between the processing plant and the pit void; where the storage volume is small and the length of pipeline corridor is long, the unit capital cost even exceeds that of the mean for in-pit TSFs with embankments.

Of particular note is that the lowest capital unit cost for storage in an ex-pit TSF is 6.6 times the lowest rate of in-pit disposal. However, the lowest unit capital cost of an ex-pit TSF is approximately half the cost of the most expensive in-pit TSF and around 1.3 times the mean cost of an in-pit TSF. Such variations serve as an illustration of the importance of appropriately estimating the cost of all potential storage options rather than making assumptions prior to developing a bill of quantities. This is further supported by the fact that the two upstream raised TSFs are only the third and fifth cheapest of the ex-pit facilities. Cheaper ex-pit storage options were possible by utilisation of valley storages on other sites, even where long pumping distances and multiple saddle dams were required in some cases.

The combination of cost and consequence category is presented in Figure 3, which reveals a general trend of lower failure consequence and cost for in-pit TSFs. In-pit TSFs with embankments tend to be similar in consequence, but lower in cost than ex-pit TSFs. However, depending on specific site characteristics, ex-pit TSFs may pose a lower failure consequence than in-pit facilities with embankments where mining continues downstream in the mining void, which results in a High C classification in four instances. Again, this is an example of the importance of considering alternative storage options fully and avoiding bias toward any storage method. The authors warn that applying the observed general trends in this paper may create such biases and each site and method should be objectively assessed on its merits for each project.

An outlier is evident in Figure 3, which is an in-pit TSF with a consequence category of Very Low and relatively high cost. This is because its realised unit capital cost was high due to it providing a relatively small storage volume and for which a long piping corridor was constructed. If this point is excluded, a correlation coefficient ( $r$ ) between cost and consequence classification of 0.47 results.

\section{$3 \quad$ Case studies}

The following case studies have been selected as they demonstrate the forward-planning and collaboration that were required to realise the benefits discussed above. Figure 5 details the comparison of the ANCOLD consequence category classification and normalised capital cost of the TSFs highlighting those included in the 
case studies. Site A was the first to adopt an in-pit solution for tailings storage with a second facility currently being implemented. Site B has for approximately 40 years stored tailings in ex-pit TSFs with a large in-pit facility currently being developed. Site $C$ has been in operation for the past seven years and has two facilities of consequence classification High C and High B in operation.

One important development that has had a significant impact on all case studies is the implementation of a TMP for each site, which is updated annually including multi-discipline review and re-evaluation of future storage options and planning. The primary objectives of the TMP are to identify safe and cost-effective options for storing tailings that are consistent with the most updated short, medium and LoM plans, facilitate communications of tailings related risks from planning to closure, develop a schedule for the management of tailings storage so that adequate planning, resource allocation and capital expenditure can be made, describe expected tailings production and achieve compliance under the Rio Tinto D5 standard, which covers the management of risks associated with the operation of tailings and water storage facilities (Rio Tinto 2020). The TMP also includes the requirements and considerations for rehabilitation of the TSFs, which further facilitate the integration of tailings and closure plans. An example of the benefits of forward planning and alignment of the tailings and closure plan is the identified opportunity of backfilling a mined-out pit with tailings reported in Latham \& Lazo-Skold (2019).

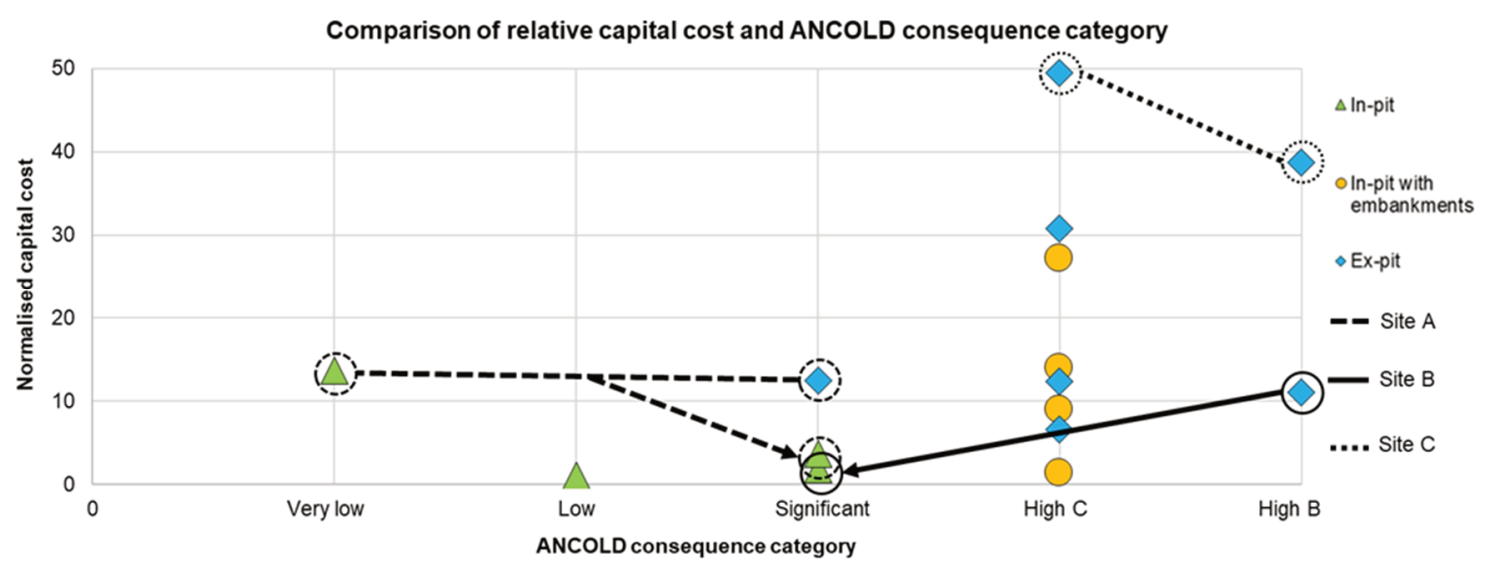

Figure 5 Comparison of ANCOLD consequence classification and normalised capital cost for the construction of the TSFs highlighting the facilities included in the case studies of Site A, Site B and Site C

\subsection{Site A}

Site A has three TSFs; one ex-pit and two in-pit facilities, one of which is currently under development. The original ex-pit TSF was commissioned along with the processing plant in 2013 and was subsequently raised by $6 \mathrm{~m}$ in 2015, for which the normalised capital cost (12.48) is presented in this paper. Both stages of this facility have an ANCOLD consequence category of Significant. Construction of the initial in-pit TSF, with an ANCOLD consequence category of Very Low and normalised cost of 13.59, was completed in 2016. A new in-pit facility comprising three nearby pits is currently being developed. The new in-pit facility has an ANCOLD consequence category of Significant and a normalised capital cost of 3.63. Its consequence classification is driven by the presence of an adjacent pit that will be actively mined whilst tailings are being deposited. This risk was identified several years in advance and allowed the design of the pit to be modified to comply with a conservative design criteria. As such, tailings storage for the second half of the original mine life (14 years) is estimated to be approximately 3.6 times less than the first half of the mine life.

Modification of the pit design is just one outcome from the formation of a well-defined multi-disciplinary team that was formed to provide input to the annual TMP updates several years ago. Successful implementation of a TMP is reliant upon the engagement of the necessary stakeholders. An example of the list of stakeholders that were engaged for tailings planning and management for Site A (as well as Site B and C) is presented in Table 1. Although not exhaustive and the exact accountabilities of each stakeholder may 
vary to meet the needs of a specific site, Table 1 highlights that a considerably varied and large set of stakeholders is required.

\section{Table 1 Integral stakeholders needed for future tailings management planning}

\begin{tabular}{ll}
\hline Stakeholder & Inputs \\
\hline Tailings engineers & $\begin{array}{l}\text { Overarching planning, consolidation of multiple discipline inputs to } \\
\text { present feasible storage solutions to LoM }\end{array}$ \\
Mine planning engineers & $\begin{array}{l}\text { Key design criteria data including tailings throughputs and yields, } \\
\text { information about pit progressions and mine waste plans }\end{array}$ \\
$\begin{array}{l}\text { Capital programme } \\
\text { coordinator and project lead }\end{array}$ & Coordination and management of the implementation of projects \\
Environmental advisers & $\begin{array}{l}\text { Guidance on site constraints (environmental receptors) and } \\
\text { environmental requirements }\end{array}$ \\
Hydrogeologist & $\begin{array}{l}\text { Assessment of impact of tailings deposition and advice on measures } \\
\text { to limit them. Anticipated dewatering rates prior to, during and after }\end{array}$ \\
tailings deposition, where required. Input to water balance
\end{tabular}

The pits currently being developed to be part of the new in-pit TSF were moved forward in the mine plan to ensure that they would be available for tailings storage as required, which was supported by regular communication between the tailings and mine planning teams. Although this was an important aspect, it was also critical to identify, study and address potential environmental impacts arising from the TSF development which was aided by inclusion of several of the above technical and advisory disciplines. The tailings engineers coordinated the group listed above and as such required varied skills and knowledge. However, in many instances the success of the development relied upon specialist input from one of the professionals listed. This was extended to the detailed design of the facilities, which was undertaken by consulting engineers.

Alternative options that were considered for the site included raising the existing ex-pit TSF and storage within all other pits currently being mined or planned in the future. This was completed on multiple occasions as part of annual reviews to the TMP and as the mine plan changed. In combination with frequent capacity tracking of the existing facilities, this process allowed for a quick reaction to changes in the mine plan in late 
2019, which saw tailings production planned for the next two years significantly increase. Sufficient capacity was available in the existing facilities; however, it was identified that a pump booster station was required to allow slurry pumping of the higher throughput of tailings to the existing ex-pit facility. Adaptation to this change required input from several disciplines, which was made easier due to the existing knowledge of the various internal specialists due to being part of the annual planning process.

\subsection{Site B}

Site B has two ex-pit facilities and an in-pit TSF that is currently under development. It commissioned a concentrator and consequently started producing tailings in 1977. Tailings were initially stored in an ex-pit facility that was subsequently replaced by another in 1992, which is now nearing capacity. Similar to Site A, coordination of a large multi-disciplinary team occurred several years ago, which has supported the development of a large in-pit facility due to be implemented in late 2021. The current ex-pit TSF has an ANCOLD consequence category of High B and a normalised cost of 10.98, calculated from its most recent raise commissioned in 2017. Alternative options considered included other pits on the site, further raising the existing ex-pit TSF, and construction of a new ex-pit TSF with an estimated normalised cost of 9.5 and High $C$ consequence category.

Despite the environmental and water management challenges posed by the new in-pit TSF as detailed in Latham \& Lazo-Skold (2019), the ANCOLD consequence category is Significant and the estimated normalised cost is 1.84 . The consequence is a result of below-ground storage meaning the need for constructed impoundment structures is avoided. The cost is relatively low due to the very large storage provided by the pit. As discussed in Latham \& Lazo-Skold (2019), the in-pit TSF also presents a superior environmental outcome in closure than if it was rehabilitated by an alternative method. Consequently, collaboration of disciplines and early planning has resulted in a reduced risk in operations and closure with a significantly lower cost of tailings storage.

\subsection{Site C}

The discussion of Site $\mathrm{C}$ is included here to demonstrate the impact on tailings management when the tailings and the mine LoM plans are not properly integrated and the value added by applying the strategic planning approach discussed above at the other sites is overlooked. Site $C$ has two ex-pit TSFs with current ANCOLD consequence categories of High $\mathrm{C}$ and High $\mathrm{B}$, and the average normalised unit capital cost for the two facilities being 44.12 .

The project scope for the second ex-pit TSF was to provide a single storage solution that would, at the time, have considered the LoM plan and was required to be implemented within the following year. This approach constrained the battery limit of the assessment. To achieve an optimal outcome, the scope should have considered all potential solutions to limit risk exposure and reduce LoM cost (or other applicable economic goal aligned with the company's strategy at the time).

When this project was being developed, there were several key stakeholders not represented, namely internal tailings engineers, process engineers, mine planners and geochemists. The key inputs that were not well addressed through these stakeholders not being involved were:

- The tailings yields were underestimated by $50 \%$ compared to actual yields (where yields represent the percentage of plant feed that will become tailings).

- The LoM was increased by 10 years soon after implementation, but was not considered in the assessment.

- The option to develop an integrated waste landform was not investigated further due to a perception there was a geochemical risk.

- In-pit storage options were only assessed utilising the pit shell for the year following the assessment date rather than the full LoM mining sequence. 
Had the above information been provided during the study and the discussion presented in this paper been applied, which would have been possible had the disciplines listed Table 1 been included, the options assessment would have likely recommended an ex-pit facility that provided sufficient storage until an in-pit solution was viable. Furthermore, given the significant high capital cost to construct the second ex-pit TSF (38.77) on Site $C$, the opinion of the authors of this paper based on initial studies conducted to date is that filtration and dry-stack of the tailings could have presented a more or at least comparable viable economic solution with a considerably lower consequence of failure. A dry-stack option would also have allowed integration within the coarse waste dump layout, further facilitating TSF closure and rehabilitation. Whilst there are many guidance documents which emphasise the consideration of long-term planning, there is less guidance on how this can be achieved. It is hoped that the above reflection of the missed opportunity for Site $\mathrm{C}$ provides an example of how best available practice could be implanted.

\section{Operational costs}

Operational costs have been excluded from the analyses of the case studies discussed above. However, it is important to consider this aspect of tailings management as it is a significant cost over the lifetime of a TSF and may therefore influence the outcome of a multi-criteria analysis. This may be especially applicable to new technologies such as filtration that require the operation and maintenance of additional plant and earthmoving equipment on site.

Most TSFs are designed with well-defined operational control requirements to ensure that the design assumptions and intended risk posed by the facility is maintained throughout its lifecycle. Active management of deposition and decant pond is also critical in at least achieving, if not optimising, in situ tailings densities and hence lowering the cost per tonne of tailings stored.

There are two main goals that expenditure on the operation of a TSF seeks to achieve:

1. Maintain, or ideally reduce, the level of risk posed by the facility to that assessed and accepted at the design phase.

2. Protect, or ideally improve, the investment made in construction of the TSF.

A comparison of annual unit capital cost (capital cost per year of storage provided) and annual unit operational cost (operational cost per tonne of tailings stored) for the 15 TSFs to the end of 2019 is shown in Figure 6. Note that the operational costs accounted for the ongoing expenses associated with the operation and maintenance of the TSFs, but did not include the costs related to power consumption. The annual unit operational cost and annual unit capital cost have been normalised by the lowset annual unit capital cost such that both axes are dimensionless. If capital and operational costs were equal, they would plot equidistant from each axis on the line plotted at an inclination of $45^{\circ}$ shown in Figure 6 . The data show that the annual capital cost is in most cases far higher than operational expenditures. The exceptions are the two lowest cost facilities, both in-pit TSFs, which provide a very large storage capacity and are in relatively close proximity to the plant. If these two facilities were on the same site, it would have been important to consider the operational cost over the intended lifetime in order to select the lowest lifetime cost. Such a situation may be more common when in-pit disposal is not an option and different alternatives to modify tailings slurry are available (thickened, paste or filtration) as well as multiple sites. 


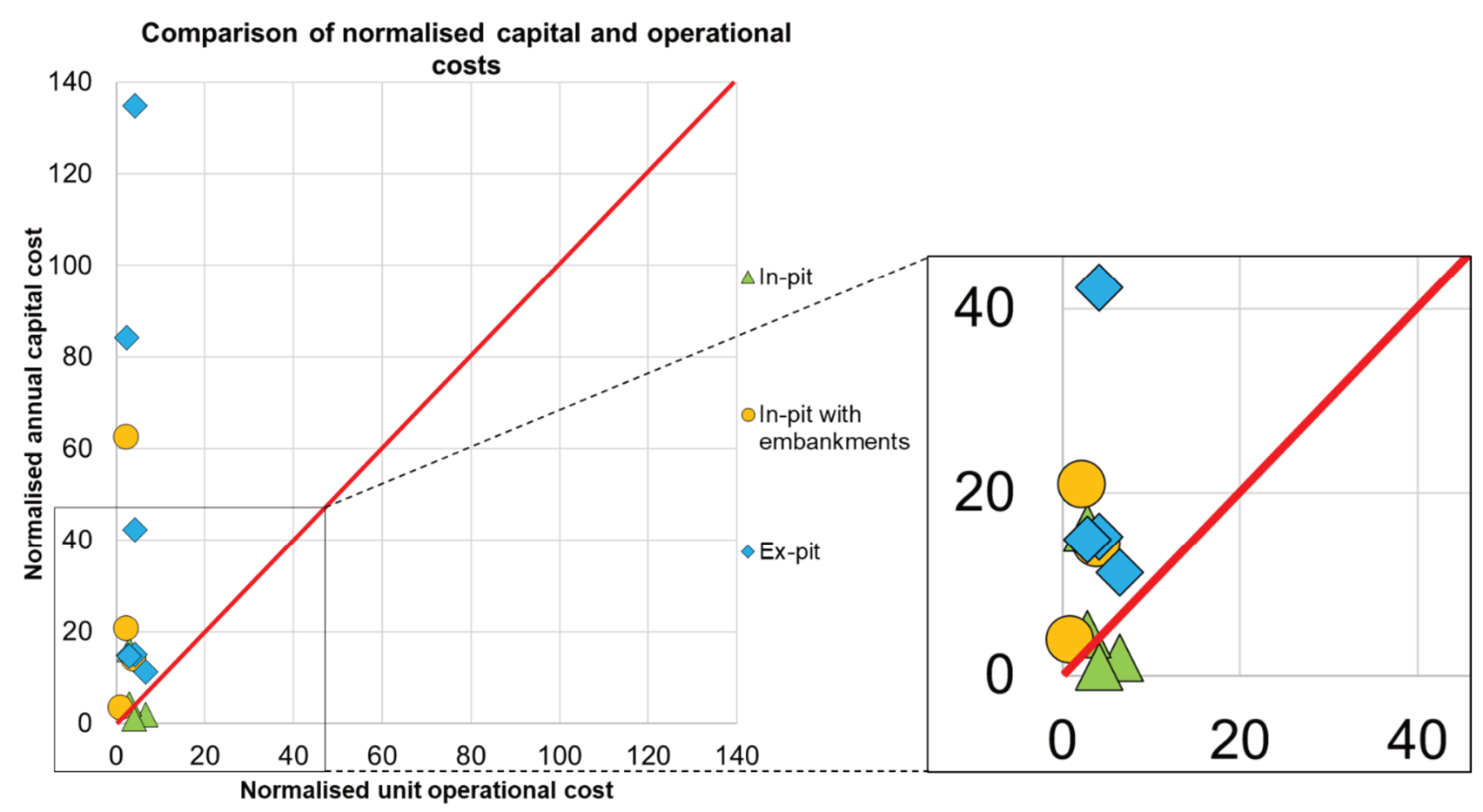

Figure 6 Comparison of normalised annual capital and unit operational costs

It is generally well accepted that the operation of TSFs significantly impacts their safety. The degree to which this applies is unique to each facility and the operational practice or control that is not achieved and associated sensitivity of the structure to it. Even if poor operational practice does not result in increased risk, it may lead to lower in situ density being achieved, which in turn will increase the unit capital cost. Given that operational costs have been shown to be significantly lower than capital costs, it is contended that the ability of the owner to safely reduce the cost of tailings storage is during the selection of storage method utilising a broadly scoped multi-criteria analysis as advocated in this paper.

\section{Discussion}

RTIO has the benefit of having multi-pit mining operations at many sites. In addition, the adoption of wet processing, which results in the production of tailings, has often commenced after above-water table mining (which only requires dry processing and consequently no tailings production) has been completed. This has meant that exhausted pits are often available for tailings storage at or near the time that tailings production is due to start. The opportunity to use mine voids for tailings storage, together with the long-term planning and active management processes that have been implemented has resulted in significant reductions in risk and even cost associated with tailings management. It is acknowledged that in-pit disposal is not an option for all mining operations, however the same process of integrated tailings management may present similar benefits in the consideration of alternative options.

It should also be mentioned that realising the optimised storage plans discussed in this paper required ongoing tracking and review of both TSF performance and mine plans over varying time horizons. Mining is a dynamic business and this is necessary to protect the benefits of conducting the studies discussed in this paper.

Considering failure consequence alone is probably not sufficient to make a well-informed decision of storage type and develop a new TSF. Consequence category has been presented as a convenient representation of risk in this paper, but in the authors' opinion it does not provide sufficient insight to optimise long-term storage schedules. For example, additional expenditure could be spent on an ex-pit facility to reduce the likelihood of failure such that a significantly lower risk is posed; this is especially important in consideration of reinforcing existing facilities where the consequence category likely will not be changed. It is therefore 
important that a risk threshold of some form is set; this is common from an economic standpoint where funding may not be available when a certain cost is exceeded and risk appetite should similarly be understood. The Global Industry Standard on Tailings Management (Global Tailings Review 2020) has effectively set such a risk-target in the form of as low as reasonably practical (ALARP). The consequence and/or risk of failure should also be considered more broadly against issues such as security of storage (or inversely, redundancy of available storage) and operational difficulty and reliability. For example, consider two alternatives with the same consequence classification:

1. A relatively cheap storage option that is very difficult to expand should achieved density be less than anticipated and require significant management to maintain in a safe state.

2. A relatively expensive storage that can be segregated into cells and easily expanded if required and requires minimal active deposition and decant management.

In this instance, if a decision was made between the two options considering only the consequence of failure, the risk exposure of the owner would vary significantly.

The case studies presented in this paper demonstrate the benefits produced by integration of long-term alignment of tailings and mine planning with input from a multi-disciplinary team of internal specialists and external consultants. In-pit disposal has required emphasis on different issues and has required greater interaction between a larger group of disciplines than the ex-pit TSFs they have replaced. Of particular note in the development of these in-pit solutions is the importance of having the right skills involved in the process of developing future storage developments. Groundwater impacts have often been found to pose the greatest risk arising from in-pit TSFs and as such inputs from hydrogeologists and geochemists were key. However, it is critical that the tailings engineer develop a representative water balance, which necessitates an accurate deposition plan that is in turn impacted by plant and thickener performance, and therefore the input of the process engineer. Hence, it is not possible to properly assess the groundwater risk without at least the four disciplines noted in this example providing input. Consequently, it appears that professional development of tailings engineers along with tailings education for associated technical disciplines is necessary for the successful management of tailings.

Operational costs have been shown to be relatively minor in comparison to capital costs for the development of TSFs for the case studies considered in this paper. However, it is cautioned that this may not be the case for different storage strategies, especially as the case studies have excluded power consumption costs. Operational costs may significantly impact the outcome of multi-criteria analysis for alternate management strategies and should be considered. Closure costs are not presented in this paper and may also have a similar impact. When evaluating storage options, it is important to recognise that the attractiveness of reducing costs in the short-term must be carefully weighed against the possibility of increasing other costs, such as the TSF closure costs, throughout the LoM and beyond.

\section{Conclusion}

This paper reported on significant risk and cost benefits that have been or are being realised through strategic tailings management planning which envisages greater integration of long-term tailings and mine planning functions at the RTIO mine sites. This has been made possible through the deployment of an integrated TMP which is annually updated to include inputs from a multi-disciplinary team. While the data presented showed that in-pit storage options tend to pose a lower consequence should a TSF failure ever occur and have been proving to be more economical over the long-term, this was not the case for all in-pit facilities thus highlighting the importance of fully considering alternative storage options and avoiding bias toward any storage method. In light of the current tailings management crisis and increasing scrutiny of the mining industry due to recent TSF failures, it is crucial that more holistic approaches are considered for the selection of a preferred tailings storage option. 


\section{Acknowledgement}

The authors acknowledge Rio Tinto for allowing publication of this work and the contribution of the authors' colleagues who have contributed to the case studies discussed in this paper.

\section{References}

ANCOLD 2012, Guidelines on the Consequence Categories for Dams, Australian National Committee on Large Dams, Hobart, 40 p.

Carneiro, A \& Fourie, AB 2020, 'Assessing the impacts of uncertain future closure costs when evaluating strategies for tailings management', Journal of Cleaner Production, vol. 247, pp. 119-173.

Department of Foreign Affairs and Trade 2016, Leading Practice Handbook: Tailings Management, Department of Foreign Affairs and Trade, viewed 12 April 2021, https://www.industry.gov.au/data-and-publications/leading-practice-handbook-tailingsmanagement

Edraki, M, Baumgartl, T, Manlapig, E, Bradshaw, D, Franks, DM \& Moran, CJ 2014, 'Designing mine tailings for better environmental, social and economic outcomes: a review of alternative approaches', Journal of Cleaner Production, vol. 84, pp. 411-420.

Fourie, AB 2012, 'Perceived and realized benefits of paste and thickened tailings for surface deposition', Journal of the Southern African Institute of Mining and Metallurgy, vol. 112, pp. 919-926.

Global Tailings Review 2020, Global Industry Standard on Tailings Management, viewed 12 April 2021 , https://globaltailingsreview.org/global-industry-standard/

International Commission on Large Dams 2001, Tailings Dams - Risk of Dangerous Occurrences, Lessons Learnt from Practical Experiences, Bulletin 121, International Commission on Large Dams, Paris.

Jewell, RJ \& Fourie, AB 2015, Paste and Thickened Tailings: A Guide, 2nd edn, Australian Centre for Geomechanics, Perth, 256 p.

Latham, CL \& Lazo-Skold, C 2019, 'Problematic pit: closure liability to operational opportunity', in AB Fourie \& M Tibbett (eds), Mine Closure 2019: Proceedings of the 13th International Conference on Mine Closure, vol. 2, Australian Centre for Geomechanics, Perth, pp. 1241-1254.

Mining Association of Canada 2019, A Guide to the Management of Tailings Facilities, Mining Association of Canada, viewed 12 April 2021, https://mining.ca/documents/a-guide-to-the-management-of-tailings-facilities-version-3-1-2019

Morgenstern, NR 2018, Geotechnical Risk, Regulation, and Public Policy, viewed 14 April 2021, https://www.victorfbdemello.com.br/arquivos/Lectures/6TH_VICTOR_DE_MELLO_LECTURE.pdf

Morgenstern, NR, Vick, SG \& Van Zyl, D 2015, Report on Mount Polley Tailings Storage Facility Breach, viewed 14 April 2021, https://www.mountpolleyreviewpanel.ca/sites/default/files/report/ReportonMountPolleyTailingsStorageFacilityBreach.pdf

Rio Tinto 2020, Management Tailings Water Storage Standard, viewed 14 April 2021, https://www.riotinto.com/search\#mainsearch_q=tailings\%20management\&main-search_e=0

Rio Tinto 2021, Tailings, viewed 23 May 2021, https://www.riotinto.com/en/sustainability/environment/tailings

Van Zyl, D 2016, Waste Not, Want Not - Rethinking the Tailings and Mine Waste Issue, viewed 14 April 2021, https://www.researchgate.net/publication/312039567_Waste_not_want_not_-_Rethinking_the_tailings_and_mine_waste_issue 